\title{
Analysis of Genetic Variability Using RAPD Markers in Paeonia spp. Grown in Korea
}

\author{
Mi Young Lim ${ }^{1,2}$, Sonali Jana ${ }^{3}$, Iyyakkannu Sivanesan ${ }^{2}$, Hyun Rho Park ${ }^{4}$, \\ Ji Hyun Hwang, Young Hoon Park, and Byoung Ryong Jeong ${ }^{1,2,3 *}$ \\ ${ }^{1}$ Division of Applied Life Science (BK21 Program), Graduate School, Gyeongsang National University, Jinju 660-701, Korea \\ ${ }^{2}$ Institute of Agriculture \& Life Science, Gyeongsang National University, Jinju 660-701, Korea \\ ${ }^{3}$ Research Institute of Life Science, Gyeongsang National University, Jinju 660-701, Korea \\ ${ }^{4}$ Institute for Natural Products, Gyeongsangbuk-do Agricultural Research \& Extension Services, Uiseong 769-803, Korea \\ ${ }^{5}$ Department of Horticultural Bioscience, Pusan National University, Miryang 627-706, Korea
}

\begin{abstract}
The genetic diversity and phylogenetic relationships of eleven herbaceous peonies grown in Korea were analyzed by random amplified polymorphic DNA (RAPD). Twenty-four decamer RAPD primers were used in a comparative analysis of these Korean peony species. Of the 142 total RAPD fragments amplified, $124(87.3 \%)$ were found to be polymorphic. The remaining 18 fragments were found to be monomorphic $(12.7 \%)$ shared by individuals of all 11 peony species. Cluster analysis based on the presence or absence of bands was performed by Jaccard's similarity coefficient, based on Unweighted Pair Group Method with Arithmetic Averages. Genetic similarity range was 0.39 to 0.90 with a mean of 0.64 . This study offered a rapid and reliable method for the estimation of variability among different peony species which could be utilized by the breeders for further improvement of the local peony species. Also, the results propose that the RAPD marker technique is a useful tool for evaluation of genetic diversity and relationship amongst different peony species.
\end{abstract}

Additional key words: cluster analysis, genetic diversity, peony, polymerase chain reaction, primers

\section{Introduction}

Peonies are popular not only as garden flowers, potted flowers, and cut flowers, but also as medicinal plants. The Paeoniaceae family embraces the genus Paeonia, including 33 species which are further divided into herbs and trees (Barzilay et al., 2002). Species in this genus are hardy perennials and ornamental plants that are popular as beautiful garden peonies. Peony species are widespread over a range of the Northern hemisphere, including Morocco, Spain, the mountainous regions of Europe, and the Mediterranean through the Caucasus mountains to Central Asia, China, Japan, and the Western United states (Rogers, 1995). The herbaceous peony is one of New Zealand's more recent export cut flowers (Fulton et al., 2001). Herbaceous peony (Paeonia lactiflora Pallas) has been cultivated in China for more than 3,900 years (Wang and Zhang, 2005). Currently, herbaceous peonies are back in fashion, since they are easy to nurture and also due to their diverse flower forms and colors. Peony also holds its place in Korean traditional medicine, since roots are very important for medicinal purposes (WHO, 1998). The root of $P$. lactiflora is mainly used for the treatment of muscular spasm, chest pains, diarrhea, blood and liver disorders, and as a general analgesic (Guo et al., 2006).

The utilization of plant genetic resources requires an acquaintance with the quantity of genetic variation that exists among the species (Vaughan, 1994). The random amplified polymorphic DNA (RAPD) fingerprinting method uses decamer (10 nucleotide length) primers for polymerase chain reaction amplification (PCR) of random segments of genomic DNA to analyze genetic diversity and phylogeny. The RAPD technique is highly favored as no prior knowledge on the genotype is required. Moreover, conclusions derived by RAPD are parallel to those of other methods, such as amplified fragment

\footnotetext{
*Corresponding author: brjeong@gmail.com

※ Received 8 November 2012; Revised 25 January 2013; Accepted 30 January 2013. This research was supported by Technology Development Program for Agriculture and Forestry, Ministry for Food, Agriculture, Forestry and Fisheries, Republic of Korea (Project No. 109096-5). Mi Young Lim was supported by a scholarship from the BK21 program, the Ministry of Education and Human Resources Development, Korea.
} 
Table 1. Peony accessions used in the evaluation of their genetic diversity.

\begin{tabular}{|c|c|c|c|c|c|}
\hline \multirow{2}{*}{ Code } & \multirow{2}{*}{ Scientific name } & \multicolumn{2}{|c|}{ Species name } & \multirow{2}{*}{ Flower form } & \multirow{2}{*}{ Flower color } \\
\hline & & English & Korean & & \\
\hline A & Paeonia japonica Miyabe et Takeda & White Peony & 백작약 & Single & White \\
\hline B & Paeonia obovata Max & Mountain Peony & 산작약 & Single & Pink \\
\hline C & Paeonia lactiflora Pall. & Jol Peony & 졸작약 & Crown & Pink and deep pink \\
\hline D & Paeonia lactiflora Pall. & 'Euiseong' & ‘의성' & Single & Red \\
\hline$E$ & Paeonia lactiflora Pall. & 'Sagok' & ‘사곡’ & Single & Pink \\
\hline $\mathrm{F}$ & Paeonia lactiflora Pall. & 'Taebaek' & ‘태백’ & Crown & Pink and white \\
\hline G & Paeonia lactiflora Pall. & 'Migang' & '미강' & Rose & Red \\
\hline $\mathrm{H}$ & Paeonia lactiflora Pall. & ‘Geopoong' & '거풍' & Crown & Red \\
\hline I & Paeonia lactiflora Pall. & 'Daecheong' & '대청' & Rose & Red \\
\hline $\mathrm{J}$ & Paeonia lactiflora Pall. & 'Kansas' & - & Rose & Deep red \\
\hline $\mathrm{K}$ & Paeonia lactiflora Pall. & 'Lilini Warrior’ & - & Single & Deep red \\
\hline
\end{tabular}

length polymorphism (AFLP) and inter simple sequence repeats (ISSR), and may be directly comparable (Nybom et al., 2004).

The present work was undertaken to estimate genetic variation in 11 peony accessions of three species using the RAPD technique for potential future use in selection, hybridization, and biodiversity assessment. There are no reports on the comparison of the genetic variations using RAPD markers in the 11 herbaceous peony species which we report in the present study.

\section{Materials and Methods}

In the present study, 9 species or cultivars of Paeonia lactiflora which are commonly grown in Korea and two wild species (Paeonia japonica and Paeonia obovata) were used (Table 1 and Fig. 1). Genomic DNA was isolated from the leaf sample of each peony species using Gene-All spin-column kit (Gene All Biotechnology Co., Ltd., Seoul, Korea). A spectrophotometer (Nanodrop 1000, Thermo Scientific, Wilmington, DE, U.S.A.) was used to check the purity of DNA by recording the absorbance at $260 \mathrm{~nm}$. Polymorphism detection was performed using the PCR-RAPD assay. The RAPD assay was carried out by using the 24 random decamer primers (Bioneer Co., Dejeon, Korea) listed in Table 2. For all PCR reactions, the reaction mixture consisted of a total volume of $20 \mu \mathrm{L}$, with $20 \mathrm{ng}$ genomic DNA, $0.5 \mu \mathrm{M}$ decamer primer, 1X PCR buffer, $0.2 \mathrm{mM}$ deoxynucleotide triphosphates (dNTP's), and 0.6 U Thermus aquaticus (Taq) DNA polymerase (Solgent, Daejeon, Korea). The PCR amplification was performed in a thermal cycler (Gene Amp PCR system 9700, Applied Biosystems, Foster City, CA, U.S.A.). The amplification profile consisted of $1 \mathrm{~min}$ at $95^{\circ} \mathrm{C}$ for preheating, followed by 40 cycles of 15 seconds at $95^{\circ} \mathrm{C}$ for denaturation,
Table 2. Random decamer primers used for RAPD with GC content $(\%)$ and melting temperature $(\mathrm{Tm})$.

\begin{tabular}{|c|c|c|c|}
\hline Primer ID & Sequence & $\begin{array}{c}\text { GC content } \\
(\%)\end{array}$ & $\begin{array}{l}\mathrm{Tm} \\
\left({ }^{\circ} \mathrm{C}\right)\end{array}$ \\
\hline A01 & 5'-CAGGCCCTTC-3' & 70 & 34 \\
\hline A08 & 5'-GTGACGTAGG-3' & 60 & 32 \\
\hline A09 & 5'-GGGTAACGCC-3' & 70 & 34 \\
\hline A13 & 5'-CAGCACCCAC-3' & 70 & 34 \\
\hline A14 & 5'-TCTGTGCTGG-3' & 60 & 32 \\
\hline A15 & 5'-TTCCGAACCC-3' & 60 & 32 \\
\hline A16 & 5'-AGCCAGCGAA-3' & 60 & 32 \\
\hline $\mathrm{A} 17$ & 5'-GACCGCTTGT-3' & 60 & 32 \\
\hline A18 & 5'-AGGTGACCGT-3' & 60 & 32 \\
\hline A19 & 5'-CAAACGTCGG-3' & 60 & 32 \\
\hline A20 & 5'-GTTGCGATCC-3' & 60 & 32 \\
\hline B01 & 5'-GTTTCGCTCC-3' & 60 & 32 \\
\hline B02 & 5'-TGATCCCTGG-3' & 60 & 32 \\
\hline B03 & 5'-CATCССССТG-3' & 60 & 32 \\
\hline B04 & 5'-GGACTGGAGT-3' & 60 & 32 \\
\hline B05 & 5'-TGCGCCCTTC-3' & 70 & 34 \\
\hline B06 & 5'-TGCTCTGCCC-3' & 70 & 34 \\
\hline B07 & 5'-GGTGACGCAG-3' & 70 & 34 \\
\hline B08 & 5'-GTCCACACGG-3' & 70 & 34 \\
\hline B09 & 5'-TGGGGGACTC-3 & 70 & 34 \\
\hline B10 & 5'-CTGCTGGGAC-3' & 70 & 34 \\
\hline B11 & 5'-GTAGACCCGT-3' & 60 & 32 \\
\hline B12 & 5'-CCTTGACGCA-3' & 60 & 32 \\
\hline B13 & 5'-TTCCCCCGCT-3' & 70 & 34 \\
\hline
\end{tabular}

30 seconds at $45^{\circ} \mathrm{C}$ for annealing, and 1 minute at $72^{\circ} \mathrm{C}$ for extension, with a final extension for 1 minute at $72^{\circ} \mathrm{C}$. Amplified PCR products were separated on $2.5 \%$ agarose gel in a Tris borate EDTA buffer at $80 \mathrm{~V}$ for two hours, stained by ethidium bromide, and photographed under the 

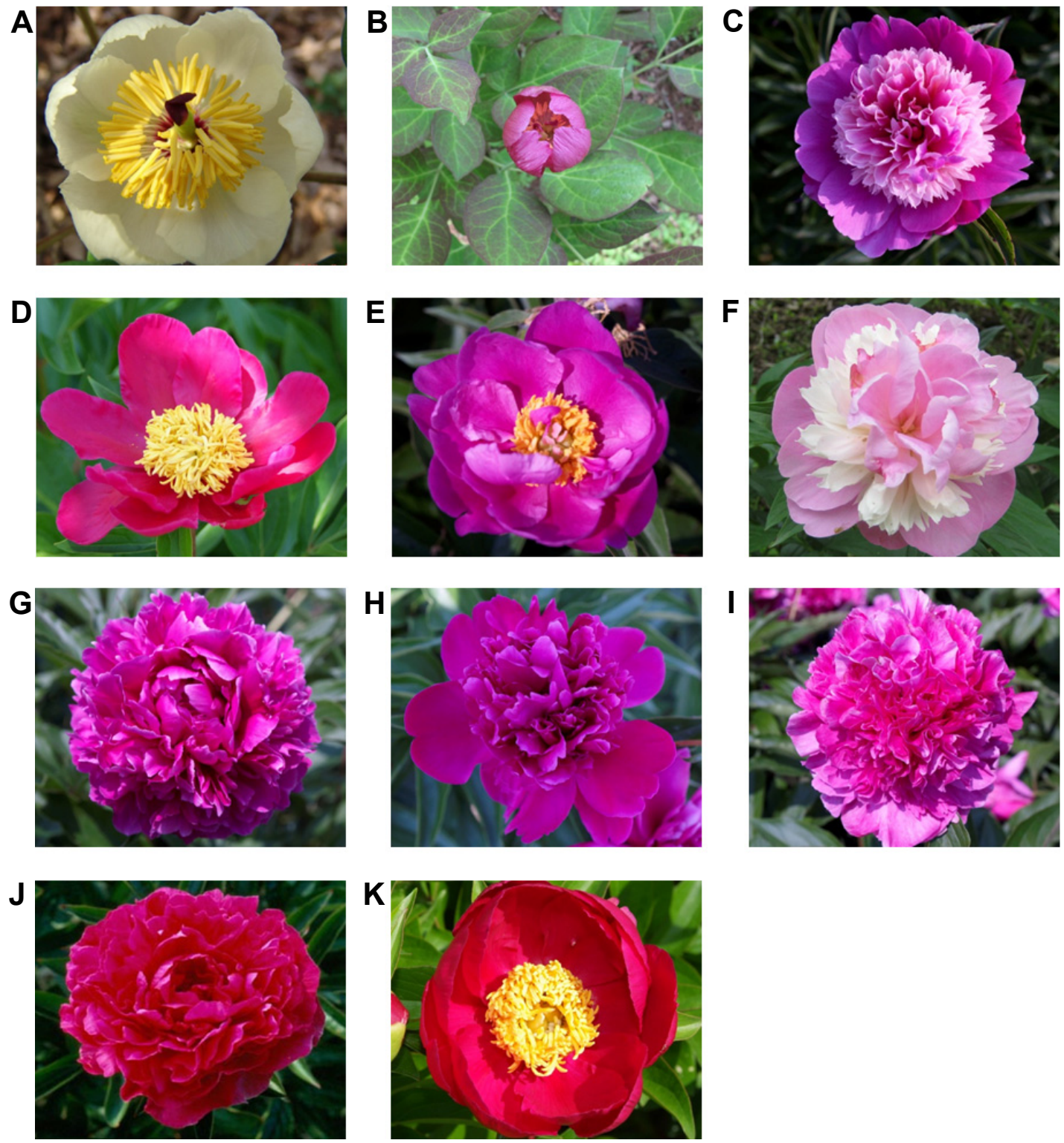

Fig. 1. Peony species used in the evaluation of their genetic diversity. A, White Peony; B, Mountain Peony; C, Jol Peony; D, 'Euiseong'; E, 'Sagok'; F, 'Taebaek'; G, 'Migang'; H, 'Geopoong'; I, 'Daecheong'; J, 'Kansas'; and K, 'Lilini Warrior'.

UV light in a gel documentation system.

\section{Data Analysis}

The DNA marker (100 bp) applied along with RAPD samples helped to determine the molecular sizes of the DNA fractions of the peony species samples. Reproducible RAPD products were scored as the presence (1) or absence (0) of a fragment by writing the data matrix NTSYS-pc software (version 2.20k, Exeter Software, Setauket, NY, U.S.A.). The genetic distances were assessed with Nei's unbiased Jaccard similarity coefficient of genetic distance measure and converted to a dendrogram based on arithmetic averages by unweighted pair group method (UPGMA) and written by using the SHAN clustering (Nei and Li, 1979).

\section{Results}

The genetic variation pattern of different peony species with primers A18, A19, and A20 are shown in Fig. 2. Genetic relationships among 11 peony species analyzed using 24 random RAPD primers showed highly reproducible, polymorphic RAPD fingerprints for discrimination of genetic variation in these peony species (Table 2). There were 10 primers with $70 \%$ GC content and 14 primers with $60 \%$ GC content. Each primer produced 1-11 fragments (average 6 per primer) with a total of 142 reproducible DNA bands (Table 3 ). Fragment sizes ranged between $250-2100$ base pairs. Of the total amplicons (142) generated, 124 (87.3\%) were found to be polymorphic, the rest $18(12.7 \%)$ were found to be 
shared by individuals of all 11 species. The maximum number (11) and minimum number (2) of amplicons were generated by primer B05 and primer B01, respectively. The percentage of polymorphism varied with each primer ranged from 33.38 to $100 \%$. All primers studied exhibited polymorphism (Table 3).

Similarity matrices of 11 species obtained using the Jaccards coefficient revealed the relationships among them (Table 4).
Similarity coefficient ranged from 0.39 between species 2 and 4 to 0.91 (between species 5 and 9) among the species evaluated.

The UPGMA dendrogram (Fig. 3) based on genetic distance grouped the 11 accessions into two clusters 1 and 2. In case of cluster 1, White Peony (Paeonia japonica) and Mountain Peony (Paeonia obovata) showed a similarity level of 0.75 , and occupied a distinct place as revealed in the dendrogram
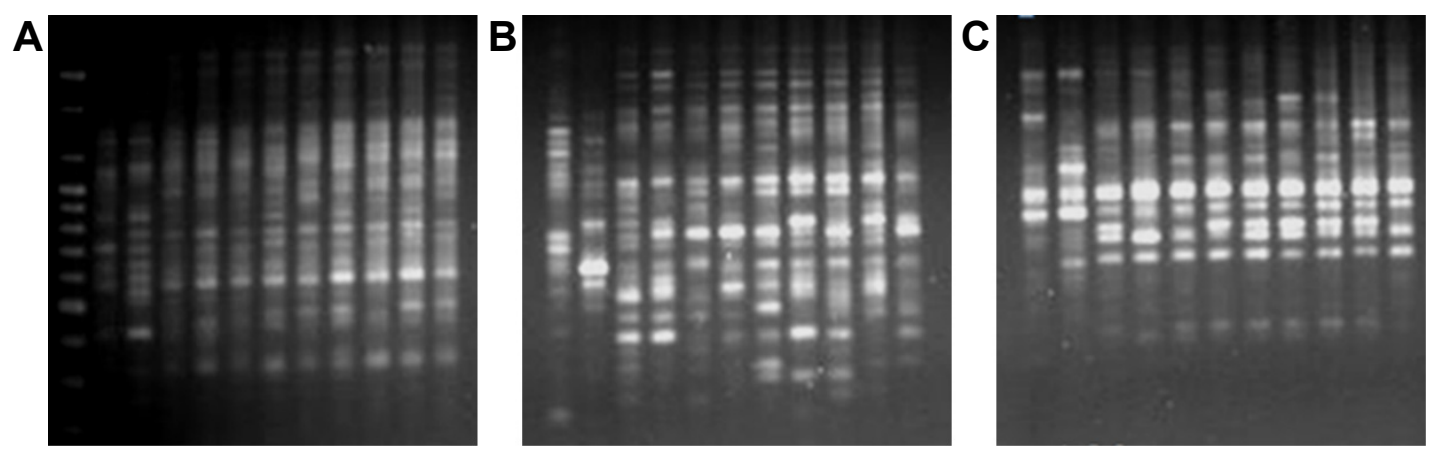

Fig. 2. RAPD banding pattern of three selected primers. Sample order from the left lane corresponds to peony species $A-K$ shown in Table 1. A, primer A18; B, primer A19; and C, primer A20.

Table 3. Total number of amplicons, number of polymorphic fragments, and percent polymorphism assayed by PCR using 24 random decamer primers in eleven peony species.

\begin{tabular}{|c|c|c|c|c|}
\hline Primer ID & $\begin{array}{l}\text { Total } \\
\text { no. of bands }\end{array}$ & $\begin{array}{l}\text { App. range of size } \\
(\mathrm{bp})\end{array}$ & $\begin{array}{l}\text { Polymorphic bands among } \\
\text { plant samples }\end{array}$ & $\begin{array}{c}\text { Polymorphism ratio among } \\
\text { plant samples }(\%)\end{array}$ \\
\hline A01 & 6 & $310-980$ & 5 & 83.3 \\
\hline A08 & 7 & $280-1100$ & 7 & 100.0 \\
\hline A09 & 9 & $250-1000$ & 7 & 77.8 \\
\hline A13 & 4 & $750-1200$ & 2 & 50.0 \\
\hline $\mathrm{A} 14$ & 4 & $280-1700$ & 4 & 100.0 \\
\hline A15 & 7 & $300-950$ & 7 & 100.0 \\
\hline A17 & 4 & $350-1700$ & 4 & 100.0 \\
\hline A18 & 5 & $310-1100$ & 4 & 80.0 \\
\hline A19 & 6 & $380-1400$ & 6 & 100.0 \\
\hline A20 & 8 & $300-1500$ & 6 & 75.0 \\
\hline B01 & 2 & $600-1100$ & 1 & 50.0 \\
\hline B02 & 3 & 310 & 1 & 33.3 \\
\hline B03 & 6 & $300-1600$ & 6 & 100.0 \\
\hline B04 & 7 & $380-1500$ & 7 & 100.0 \\
\hline B05 & 11 & $290-1000$ & 10 & 90.9 \\
\hline B06 & 3 & $500-1700$ & 2 & 66.7 \\
\hline B07 & 8 & $400-2100$ & 7 & 87.5 \\
\hline B08 & 8 & $300-1100$ & 7 & 87.5 \\
\hline B09 & 7 & $580-1300$ & 7 & 100.0 \\
\hline B10 & 4 & $280-1100$ & 2 & 50.0 \\
\hline B11 & 10 & $450-1100$ & 10 & 100.0 \\
\hline B12 & 3 & $400-450$ & 2 & 66.7 \\
\hline B13 & 10 & $320-2000$ & 10 & 100.0 \\
\hline Total no. & 142 & & 124 & 87.3 \\
\hline
\end{tabular}


Table 4. Similarity matrix of peony species analyzed using Nei's original measures of genetic identity.

\begin{tabular}{|c|c|c|c|c|c|c|c|c|c|c|c|}
\hline Row/Column & $A$ & $B$ & $\mathrm{C}$ & $\mathrm{D}$ & $E$ & $\mathrm{~F}$ & $G$ & $\mathrm{H}$ & $\mathrm{I}$ & $\mathrm{J}$ & $\mathrm{K}$ \\
\hline$A$ & 1.000 & & & & & & & & & & \\
\hline B & 0.748 & 1.000 & & & & & & & & & \\
\hline C & 0.481 & 0.427 & 1.000 & & & & & & & & \\
\hline D & 0.477 & 0.397 & 0.902 & 1.000 & & & & & & & \\
\hline$E$ & 0.506 & 0.451 & 0.908 & 0.853 & 1.000 & & & & & & \\
\hline $\mathrm{F}$ & 0.490 & 0.425 & 0.882 & 0.863 & 0.857 & 1.000 & & & & & \\
\hline G & 0.490 & 0.448 & 0.880 & 0.825 & 0.888 & 0.840 & 1.000 & & & & \\
\hline $\mathrm{H}$ & 0.484 & 0.478 & 0.883 & 0.831 & 0.852 & 0.863 & 0.858 & 1.000 & & & \\
\hline I & 0.506 & 0.440 & 0.876 & 0.868 & 0.908 & 0.882 & 0.902 & 0.855 & 1.000 & & \\
\hline J & 0.477 & 0.448 & 0.868 & 0.837 & 0.877 & 0.863 & 0.848 & 0.876 & 0.880 & 1.000 & \\
\hline $\mathrm{K}$ & 0.487 & 0.434 & 0.900 & 0.847 & 0.897 & 0.861 & 0.858 & 0.852 & 0.8777 & 0.881 & 1.000 \\
\hline
\end{tabular}

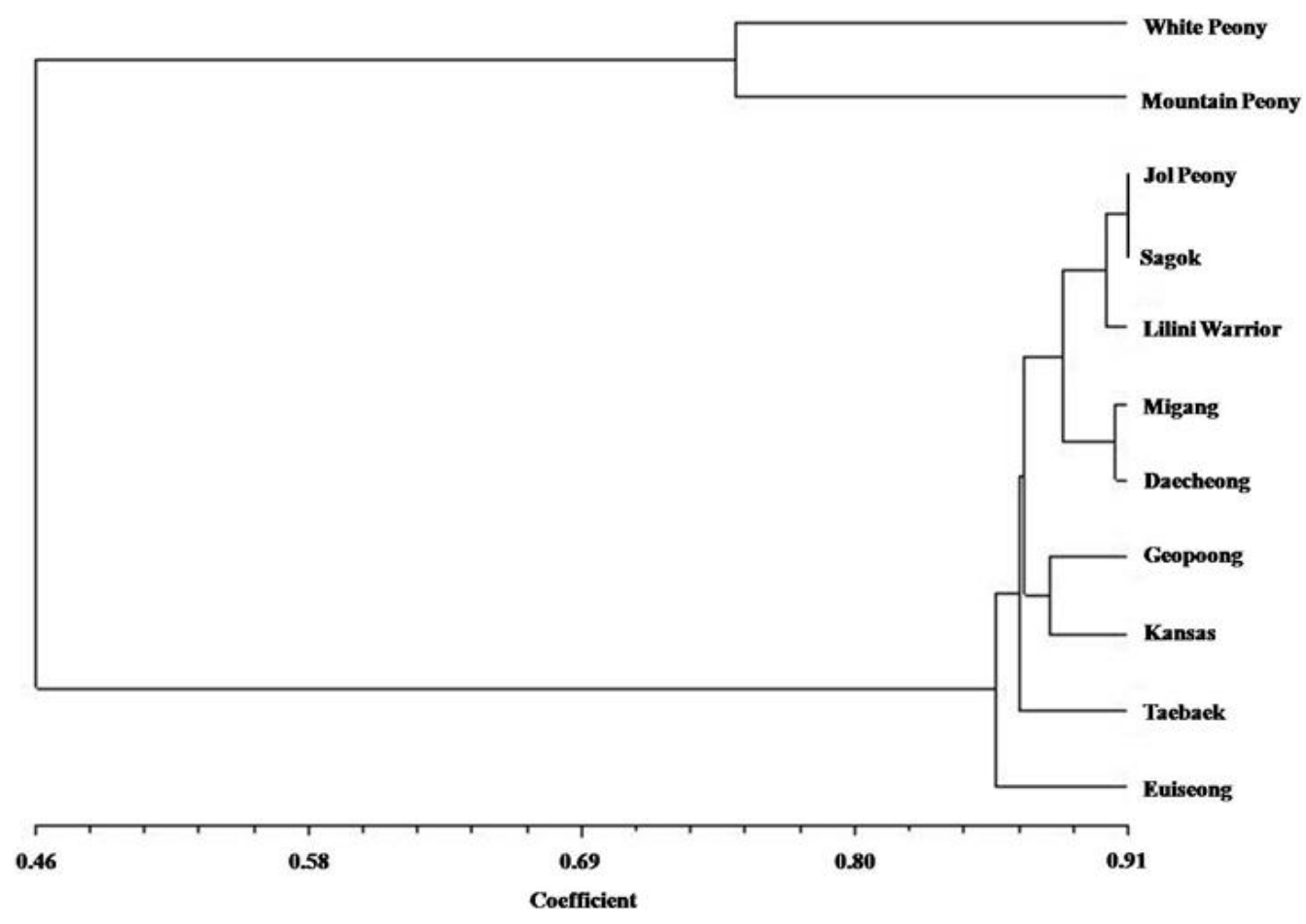

Fig. 3. Dendrogram (UPGMA) patterns showing genetic relationships in 11 species of peony analyzed in this study.

constructed (Fig. 3). The cluster 2 was composed of all 9 cultivars of Paeonia lactiflora, and differentiated into many sub-clusters according to their similarities. The highest value of similarity coefficient 0.902 was observed between 'Jol Peony' and 'Sagok'. A similar level of similarity coefficient 0.91 has been found in 'Jol Peony' and 'Lilini Warrior', and 0.91 by 'Lilini Warrior' and 'Kansas'.

These RAPD markers demonstrated striking genetic differentiations among the peony species examined.

\section{Discussion}

Paeonia lactiflora is widely distributed in Korea. Extensive studies have been carried out on the morphological diversity and horticultural attributes of peonies (Hosoki et al., 1997). However, differentiation of peony species through morphological features is ineffectual and imprecise. Morphological characters are often limited in number, usually have complex inheritance patterns, and are vulnerable to environmental conditions. Thus, molecular markers, which portray a fraction of the genome sequence composition, are highly useful to assess and to utilize the genetic variability for breeding programs. Researchers have studied genetic variation in peony species collections using various molecular techniques including, sequence related amplified polymorphism (SRAP), AFLP, RAPD, and simple sequence repeats (SSR) markers (Cheng 
et al., 2011; Hao et al., 2008; Hosoki et al., 1997; Hou et al., 2006).

In the present study, we tried to draw a relationship among the herbaceous peonies. White Peony and Mountain Peony have been originated from Arietina-Officinalis group $\times$ unknown extinct species, they share same parents and thus have been grouped into sister groups (Sang, 1995). They show distinctive morphological characteristics in comparison to other peony cultivars (Fig. 1). Classification based on DNA sequence variation revealed by RAPD clearly showed that these two wild species had undergone evolutionary diversification from the domesticated Paeonia lactiflora. Genetic diversity was also found within the commercial cultivars of Paeonia lactiflora. Nine peony cultivars in the cluster 2 have similarities among them, and the similarity coefficient ranged between 0.82 and 0.91 . Relatively high similarity coefficients imply that Korean peony cultivars have a narrow genetic base and might shared common parentages in breeding process. However, it is difficult to make this conclusion, since reliable information for breeding pedigree of these cultivars is not available. Nevertheless, the fact that cultivars with similar flower colour tended to group under the same node indicates that peony breeding materials have been possibly inter-hybridized with the flower colour as a major commercial trait.

The results of our study proved the usefulness of RAPD for DNA fingerprinting of Peony plants. The study revealed that RAPD primers which are often reported to be unreliably reproducible produced appreciable amplicons, sufficient to demarcate all peony accessions. The dendrogram also established genetic relatedness among different peony accessions (Fig. 3). The study confirms the suitability of RAPD as a reliable, simple, easy to handle, and elegant tool in molecular diagnosis of different peony plants. It has also been reported by Haw (2000) that this method of RAPD technique using immature leaves has provided a great deal of new information on the taxonomy, geographical distribution, and ecological habitats of wild tree peonies. Besides, Hao et al. (2008) have demonstrated that SRAP markers were effective on identifying peony species, section Moutan, section Paeonia, and intersectional and intrasectional hybrids of peony.

To summarize, the RAPD marker technique was found to be an informative tool to analyze the genetic structure of different species and cultivars of peony. In spite of their morphological identity, a substantial polymorphism was observed among the peony species under study. This study revealed the average genetic variation among the peony cultivars in Korea and usefulness of RAPD for cultivar identification. A narrow genetic background also indicated the necessity to introduce more diverse breeding germplasm for new cultivar development in peony.

\section{Literature Cited}

Barzilay, A., H. Zemah, and R. Kamenetsky. 2002. Annual life cycle and floral development of 'Sarah Bernhardt' peony in Israel. HortScience 37:300-303.

Cheng, Y., C.H. Kim, D. Shin, S.M. Kim, H.M. Koo, and Y.J. Park. 2011. Development of simple sequence repeats (SSR) markers to study diversity in the herbaceous peony (Paeonia lactiflora). J. Med. Plant Res. 5:6744-6751.

Fulton, T.A., A.J. Hall, and J.L. Catley. 2001. Chilling requirements of Paeonia cultivar. Sci. Hort. 89:237-248.

Guo, D., Y. Guan, and H. Guo. 2006. A new phenolic glycoside from Paeonia lactiflora. Fitoterapia 77:613-614.

Hao, Q., Z.A. Liu, Q.Y. Shu, R. Zhang, J.D. Rick, and L.S. Wang. 2008. Studies on Paeonia cultivar and hybrids identification based on SRAP analysis. Hereditas 145:38-47.

Haw, S.G. 2000. Paeonia ostii in Britain. New Plantsman 7:160-163.

Hosoki, T., D. Kimura, R. Hasegawa, T. Nagasako, K. Nishimoto, K. Ohta, M. Sugiyama, and K. Haruki. 1997. Comparative study of Chinese tree peony cultivar by random amplified polymorphic DNA (RAPD) analysis. Sci. Hort. 70:67-72.

Hou, X.G., W.L. Yin, J.J. Li, and H.F. Wang. 2006. AFLP analysis of genetic diversity of 30 tree peony (Paeonia suffruticosa Andr.) cultivar. Sci. Agric. Sin. 39:1709-1715.

Nei, M. and W.H. Li. 1979. Mathematical model for studying genetic variation in terms of restriction endonucleases. Proc. Natl Acad. Sci. USA 79:5269-5273.

Nybom, H., G. Esselink, and G. Werlemark. 2004. Microsatellite DNA marker inheritance indicates preferential pairing between two highly homologous genomes in polyploidy and hemisexual dog roses, Rosa L. sect Caninae DC. Hereditas 92:139-150.

Rogers, A. 1995. Paeonies. Timber Press Inc., Portland, OR, USA.

Sang, T. 1995. Phylogeny and biogeography of Paeonia (Paeoniaceae). Ph.D Diss., Ohio State University, Columbus, OH.

Vaughan, D.A. 1994. The wild relatives of rice: A genetic resource handbook. International Rice Research Institute, Los Banos, Philippines.

Wang, J.G. and Z.S. Zhang. 2005. Cultivation and propagation, p. 17. In: J.G. Wang and Z.S. Zhang (eds.). Herbaceous peonies of China. China Forestry Publishing House, Beijing, China.

World Health Organization (WHO). 1998. Paeonia lactiflora var. hortensis Makino; Paeonia suffruticosa Andrews, p. 188-191. In: Medicinal plants in the Republic of Korea. WHO Regional Office for the Western Pacific, Manila, Philippines. 